\title{
Global health initiatives in cardiothoracic surgery: ethical considerations and guidelines
}

Kathleen N Fenton, William M Novick, John W Entwistle, 3rd, Susan D Moffatt-Bruce, Robert M Sade, the Cardiothoracic Ethics Forum

16 October 2020

Worldwide inequalities in the availability of health care are associated with differences in health indices such as treatment outcomes, life expectancy and early childhood mortality. Although cardiovascular and pulmonary disease are leading causes of death worldwide [1] surgical treatment for these problems is either insufficient or absent in a large portion of the world $[2,3]$. Attempts to address this issue began with efforts to bring individual patients to major centres for treatment and isolated medical mission trips; later, sustainable surgical programmes were established in target countries [4, 5].

Cardiothoracic surgery has become commonplace in most of the developed nations in the world. Operations that were once considered high risk are now routine, and surgical outcomes are continually improving. As a result of these improvements, it is now possible to provide safe and effective care for patients with complex heart disease even in areas with severely limited

This is the author's manuscript of the work published in final edited form as:

Fenton, K. N., Novick, W. M., Entwistle, J. W., Moffatt-Bruce, S. D., Sade, R. M., \& Cardiothoracic Ethics Forum. (2021). Global health initiatives in cardiothoracic surgery: Ethical considerations and guidelines. European Journal of Cardio-Thoracic Surgery: Official Journal of the European Association for Cardio-Thoracic Surgery, 59(1), 4-7. https://doi.org/10.1093/ejcts/ezaa213 
resources. As a result, cardiothoracic surgical global health initiatives (CTSGHIs) have expanded dramatically over the last 25 years. A growing number of publications describe how to assist low- and middle-income countries (LMICs), the outcomes of such assistance and special surgical considerations when working in LMICs [6-8].

Caring for those in need, especially as most or all efforts are done with the best of intentions, is seen as a sign of solidarity between those in the developed world and the LMICs, an important intangible benefit [9]. At the same time, criticism of humanitarian work in general-and in particular the practice of taking short-term 'brigades' to provide medical or surgical care-has increased $[10,11]$. The harshest critics have referred to service-oriented trips as 'surgical tourism', emphasizing a lack of respect for the values and culture of the host country [12, 13]. Clearly, risks of harm associated with medical service trips may include visiting providers' lack of familiarity with local needs and problems [9] and fostering dependency while displacing local providers [14]. Furthermore, efforts may be both costly and ineffective [15].

Although CTSGHIs are controversial, when done in the right way, they can benefit everyone involved. For that reason, ethical standards for global humanitarian work are clearly needed. One recent paper outlines ethical principles for global health activities in general [16], and the American College of Physicians has set guidelines for its members regarding medical trips [17]. The purpose of this paper is to describe specific ethical issues affecting CTSGHIs and to provide guidelines for the ethical conduct of cardiothoracic surgeons, both those in leadership positions 
in humanitarian organizations responsible for the establishment of CTSGHIs and for those who participate as volunteers.

\section{Ethical Foundation}

As cardiothoracic surgeons, we recognize that our first responsibility is to safeguard the welfare of our patients, irrespective of demography and location; this is reflected in the first point (1.1) of both the Society of Thoracic Surgeons and the American Association for Thoracic Surgery codes of ethics: when caring for patients, members must hold the patient's welfare paramount $[18,19]$. Although the obligation to our patients always takes precedence, we also have responsibilities towards those we have committed to teach, to our professional colleagues, and to society as a whole. These obligations are frequently complex, can potentially cause conflict, and when working in low-resource settings can create even more stressful ethical dilemmas. How specific ethical issues may play out in the course of CTSGHIs is described in the following sections.

\section{Site Selection and Early Organization}

All CTSGHIs begin well before travel arrangements are made, both for the programme development leaders and for each individual surgeon-volunteer. Responsibility for travel expenses, travel equipment, and, if needed, malpractice coverage must be determined in advance. 
Target sites do not have adequate cardiothoracic surgery for many reasons, and CTSGHIs may ultimately fail $[8,20]$; although these issues are beyond the scope of the current discussion, they explain why it is critical for programme organizers and host country stakeholders (the local health care team, ministry of health or other government representatives, and hospital and community leaders, among others) to discuss in advance the goals for the project and what obstacles they have faced in the past and anticipate in the future $[18,21]$.

The need to jointly set goals and identify obstacles rests on the ethical principle of autonomy: the host stakeholders are in the best position and should be empowered to make decisions regarding what is best for their country. Joint goal setting is also pragmatic: the programme success requires meeting the needs of the local team first and foremost, as opposed to fulfilling the wishes of the donor organization. Other ethical principles that apply include distributive justice and beneficence: the local community and national ministry of health can place the prospect of cardiothoracic surgical care in the broader context of the needs of their population and health care system as a whole.

Advanced planning for CTSGHIs also includes programme organizers simultaneously working with funders and with potential volunteers. These interactions must be carried out with honesty and transparency regarding expectations for the number and type of patients to receive care, realistic prospects for programme development and a straightforward depiction of what alternative care models might already exist. Students, residents and fellows may volunteer but will participate at the same level they would at their home institutions; they 
should not interfere with the primary purpose of educating the local staff. CTSGHIs should not be considered opportunities to perform procedures that are outside the scope of practice at home or for the purpose of conducting unregulated research.

\section{Preparation Before the Journey}

Once the site has been selected and the team has been organized, preparation can begin for an individual trip or multiple missions. This requires close coordination with the host providers. Selection of potential patients or types of patients should be done in advance of the venture, according to the resources and personnel available, taking into account both the host team and the visiting staff.

Vigorous effort must be made to educate all parties involved. Host organizers can prepare their staffs by helping them to anticipate the number and type of patients who will be seen, and by explaining to them the exact preparation needed and anticipated roles and responsibilities. The visiting volunteers and staff should be educated about the anticipated patients, the resources available, the experience of their local colleagues and the cultural norms, including everything from food and dress to interpersonal relations and religious and cultural positions on end-of-life care. Acquiring this understanding before the journey can enable more efficient resolution of problems that arise, sometimes precipitously, while the visitors are in the host community.

\section{While In the Country}


Although many ethical dilemmas can be averted with careful preparation and education, problems will certainly arise during the course of any CTSGHI. In particular, even though 'appropriate' patients may have been carefully selected in advance, it is not uncommon to either discover errors in diagnosis or to be confronted with a patient who was not listed for a procedure but who requires urgent intervention.

There are no easy answers to such problems, but they can be evaluated according to ethical principles. The principle of non-maleficence dictates that this patient should not be harmed. Intervention should not be offered to a patient who is not likely to gain benefit; the patient might be too sick or the intervention too complicated for the individual practitioner, the team as a whole or the resources available, including resources for postoperative care after the visitors have left.

A secondary but nonetheless real concern is that other patients should not be harmed. When personnel and other resources are limited, operating on a high-risk patient might put at risk the other patients who are in the intensive care unit (ICU) or on the ward if limited resources are diverted from them. Also at risk are other patients expecting intervention whose procedure might be cancelled due to lack of resources, such as available space in the ICU. Finally, compromising the position of our local colleagues and potential future patients should be avoided; support from the government and the community is put at risk when outcomes are poor. Balancing responsibilities to individual patients, to colleagues and to the local community as a whole may seem difficult to achieve but usually can be accomplished in practice. 
Several other issues may arise relating to patient selection and surgical scheduling. It is of paramount importance that all the practitioners caring for patients must work within their customary scope of practice. As team leaders, surgeons must consider not only their own personal experience with a particular type of patient or procedure, both in general and in lowresource settings, but also the experience of the anaesthesiologist, perfusionist and ICU team. The types of patients who can undergo operations are frequently limited by issues that seldom arise in our home institutions, such as blood product availability or reliability of the oxygen supply. Finally, particularly near the end of a short-term trip, consideration should be given to what complications might occur and who will be able to manage them after the visiting team leaves. The question of whether to operate on the last day or two of a trip is complicated and should be discussed in detail in advance with the local team.

In most situations, the long-term goal of CTSGHIs is to foster the development of sustainable surgical programmes, so mentoring the local providers is a key element. Patients are cared for jointly by the visitors and the local team. Procedures may be performed by the visitors with the local providers observing or assisting, or by the local providers with the visitors assisting, supervising or merely advising. Ideally, the same mentors should be developing an ongoing relationship with practitioners in the same sites; this promotes a gradual transfer of experience and responsibility over time. Because one of the primary purposes of CTSGHIs is to mentor the local health care team and students, the visiting team students and residents should not displace the local team. Visiting residents and students can work closely with their local 
colleagues for mutual benefit. Establishing expectations in an organized fashion from the start can maximize benefits for all involved [22]. In all cases, based on the principle of respect for persons, the operating surgeon, whether local or visitor, should participate in all aspects of patient care, including preoperative evaluation, obtaining informed consent and continuing postoperative care.

The CTSGHI and host organizers should ensure the availability of qualified interpreters who not only understand English (or the visiting team's language) and are fluent in the local language but are well versed in medical terminology in both languages. This is particularly important for postoperative intensive care and appropriate communication of orders and instructions.

While caring for complex patients in resource-limited environments, shortages of necessary medications and supplies are frequent. In this situation, an ethical dilemma might appear: can it ever be appropriate to use expired medications and supplies, or to resterilize and reuse 'singleuse only' disposable equipment? Although some have categorically stated that such items must never be used $[15,16]$, available evidence suggests that expiration dates are often 'soft', that products may often or even usually be safe and effective long after the stated expiration date [23], and that even the US government maintains a list and inventory of such products that can be distributed in case of urgent or emergent need [24].

Arguments against use of these products include appeals to justice and non-maleficence: if they are not deemed safe for patients at home, they should not be used abroad. Contrary to this 
position, however, appeal may be made to the principle of beneficence to argue in favour of their use, in cases in which there are no other options: use of an expired item may make it possible to perform a procedure or care for a patient in cases where it otherwise would not be feasible. Following these principles, expired medications and expired or reused supplies can be used when all of the following circumstances apply: the use is necessary because there are no other options, such medications and supplies are legal or allowable in the host country, and the local providers (and, if appropriate, the involved patients) know and agree with their use.

Finally, visiting teams must learn about and respect local norms, customs and values when they might alter patient care, including, in particular, different beliefs and practices regarding the end of life. Patient modesty should always be respected, and what that means can vary greatly from one culture to another. Visiting team members also should pay attention to their own attire; arriving at the hospital dressed as vacationers rather than as doctors and nurses may contribute to the criticism that visiting surgeons do not treat local patients with the same respect as they treat their own. Respecting local norms does not mean responding positively to them in every case, however. Visiting team members are not obligated to do anything that they would personally consider clearly unethical.

\section{After the Journey}

At or near the end of any CTSGHI, ideally while still in the host country, a formal or informal discussion to review the experience with all involved could be helpful. This debriefing might 
include a structured discussion of the patients, what went well, what could be improved, how contact will be maintained between the local providers and their mentors as patient recovery continues and what plans can be made for subsequent initiatives. In addition, reviewing travel arrangements, local staffing and any cultural lessons learned on both sides can be valuable.

These discussions could be followed later by debriefing of the volunteers and staff of the visiting team, as well as host stakeholders. The results of these debriefings should be documented in both English and the host local language when possible, and should be made available to the CTSGHI organization as well as to the hosts in order to improve future endeavours. A CTSGHI database of patient demographics, diseases treated, procedures performed and long-term outcomes can help to improve understanding of heart disease in the host countries and to assess the needs for ongoing support.

\section{Ethical Guidelines for Cardiothoracic Surgery Global Health Initiative}

1. Responsibility to the patient is paramount and requires that surgeons should:

a) offer procedures to patients who have a reasonable chance of benefitting from them, based not only on their diagnosis and condition but also on the resources and personnel available;

b) operate within their normal scope of practice and ensure that other practitioners do so as well;

c) if performing the operation, personally evaluate the patient before surgery, explain the surgery (with a competent interpreter if necessary) and care for the patient after surgery. 
2. Responsibility to the local providers and to other local stakeholders requires that the visiting medical team should:

a) emphasize teaching and empowering the local staff;

b) avoid initiatives that are service-only without efforts at teaching or programme building, except in unusual circumstances;

c) allow a limited number of visiting trainees for surgery, anaesthesia and intensive care to participate with the understanding that the local trainees will receive priority;

d) clearly outline programme organization and goals in advance for all stakeholders, including local providers, ministries of health and others, and should develop plans in keeping with local needs and priorities;

e) respect local norms, priorities and customs.

3. Responsibility to volunteers and other participants requires that the visiting team leaders should:

a) clarify for all members of the visiting team the time investment and sources of funding for travel expenses and any needed salary support;

b) make available details related to the mission so that volunteers can align their own expectations and goals with those of both the sponsoring organization and the specific CTSGHI;

c) provide volunteers with pre-departure education that includes information regarding logistics, available resources, local personnel and cultural norms;

d) identify staff or seasoned volunteers who can serve as resources for questions and concerns while in the country; 
e) debrief staff and volunteers after the trip whenever possible.

4. Responsibility to donors and other payers requires that surgeons within the CTSGHI organization should ensure that:

a) fund-raisers give prospective donors honest and transparent information in advance regarding local needs, goals and expected results, including both patient outcomes and programme building;

b) all sponsors are informed of the results after completion of each CTSGHI, including clinical outcomes, local team education and lessons learned.

\section{Funding}

R.M.S. role in this publication was supported by the South Carolina Clinical \& Translational Research Institute, Medical University of South Carolina's Clinical and Translational Science Award Number UL1TR001450. The contents are solely the responsibility of the authors and do not necessarily represent the official views of the National Center for Advancing Translational Science of the National Institutes of Health. K.N.F. is an employee of the National Heart, Lung, and Blood Institute (NHLBI), National Institutes of Health (NIH). The comments expressed here are those of the authors, and do not reflect official positions of the NHLBI or NIH.

\section{Conflict of interest: none declared.}




\section{References}

[1] GBD 2017 Causes of Death Collaborators. Global, regional, and national age sex-specific mortality for 282 causes of death in 195 countries and territories, 1980-2017: a systematic analysis for the Global Burden of Disease Study 2017. Lancet 2018;392:1736-88.

[2] Neirotti R. Paediatric cardiac surgery in less privileged parts of the world. Cardiol Young 2004;14:341-6.

[3] Cox JL. Presidential address: changing boundaries. J Thorac Cardiovasc Surg 2001;122:413-18.

[4] Young JN, Everett J, Simsic JM, Taggart NW, Litwin SB, Lusin N et al. A stepwise model for delivering medical humanitarian aid requiring com-plex interventions. J Thorac Cardiovasc Surg 2014;148:2480-9.

[5] Novick WM, Stidham GL, Karl TR, Arnold R, Ani c D, Rao SO et al. Paediatric cardiac assistance in developing and transitional countries: the impact of a fourteen year effort. Cardiol Young 2008;18:316-23.

[6] Bolton WS, Aruparayil N, Quyn A, Scott J, Wood A, Bundu I et al. Disseminating technology in global surgery. Br J Surg 2019;106:e34-43.

[7] Novick WM, Sandoval N, Lazorhysynets VV, Castillo V, Baskevitch A, Mo X et al. Flap valve double patch closure of ventricular septal defects in children with increased pulmonary vascular resistance. Ann Thorac Surg 2005;79:21-8.

[8] Fenton KN, Castillo SH, Claro CD, Novick WM. Teamwork and program organization in developing countries. World J Pediatr Congenit Heart Surg 2011;2:219-24. 
[9] Martiniuk AL, Manouchehrian M, Negin JA, Zwi AB. Brain gains: a litera-ture review of medical missions to low and middle-income countries. BMC Health Serv Res 2012;12:134. [10] Zitzman E, Berkley H, Jindal RM. Accountability in global surgery mis-sions. BMJ Glob Health 2018;3:e001025.

[11] Bauer I. More harm than good? The questionable ethics of medical vol-unteering and international student placement. Trop Dis Travel Med Vaccines 2017;3:5.

[12] Welling DR, Ryan JM, Burris DG, Rich NM. Seven sins of humanitarian medicine. World J Surg 2010;34:466-79.

[13] Abelson R, Rosenthal E. Charges of Shoddy Practices Taint Gifts of Plastic Surgery. New York Times, November 24, 1999. https://www.nytimes. com/1999/11/24/world/charges-ofshoddy-practices-taint-gifts-of-plas tic-surgery.html (18 August 2020, date last accessed).

[14] DeCamp M. Scrutinizing global short-term medical outreach. Hastings Cent Rep 2007;37:21-3.

[15] DeCamp M. Ethical review of global short-term medical volunteerism. HEC Forum 2011;23:91-103.

[16] Lasker JN, Aldrink M, Balasubramaniam R, Caldron P, Compton B, Evert J et al. Guidelines for responsible short-term global health activities: developing common principles. Global Health 2018;14:18.

[17] DeCamp M, Lehmann Jaeel SL, Horwitch P; for the ACP Ethics, Professionalism and Human Rights Committee. Ethical obligations regarding short-term global health clinical experiences: an American College of Physicians position paper. Ann Intern Med 2018;168:6517. 
[18] Society of Thoracic Surgeons Code of Ethics. https://www.sts.org/aboutsts/policies/code-ethics (18 March 2020, date last accessed).

[19] American Association for Thoracic Surgery Code of Ethics. https://www. aats.org/aatsimis/AATSTest/Association/About/Governance/By-Laws_ and_Policies/Code_of_Ethics.aspx (18 August 2020, date last accessed). [20] Fenton KN, Cardarelli M, Molloy F, Novick W. Establishing sustainable cardiothoracic surgery programs in underserved countries. Thorac Cardiovasc Surg 2018;66:661-6.

[21] Dearani JA, Jacobs JP, Bolman RII, Swain JD, Vricella LA, Weinstein S et al. Humanitarian outreach in cardiothoracic surgery: from setup to sus-tainability. Ann Thorac Surg 2016;102:1004-11.

[22] Butler M, Drum E, Evans FM, Fitzgerald T, Fraser J, Holterman AX et al. Guidelines and checklists for short-term missions in global pediatric sur-gery: recommendations from the American Academy of Pediatrics Delivery of Surgical Care Global Health Subcommittee, American Pediatric Surgical Association Global Pediatric Surgery Committee, Society for Pediatric Anesthesia Committee on International Education and Service, and American Pediatric Surgical Nurses Association, Inc. Global Health Special Interest Group. J Pediatr Surg $2018 ; 53: 828-36$.

[23] Cantrell L, Suchard JR, Wu L, Gerona R. Stability of active ingredients in long-expired prescription medications. Arch Intern Med 2012;172: 1685-6.

[24] Lyon RC, Taylor JS, Porter DA, Prasanna HR, Hussain AS. Stability profiles of drug products extended beyond labeled expiration dates. J Pharm Sci 2006;95:1549-60. 